\title{
PROSES PEMUTIHAN KAOLIN CICALENGKA UNTUK PELAPIS KERTAS
}

\section{BLEACHING PROCESS OF KAOLIN CLAY FROM CICALENGKA FOR PAPER COATING}

\author{
Lienda Aliwarga \\ Program Studi Teknik Kimia, Institut Teknologi Bandung, \\ Jl.Ganesha no.10, Bandung 40132. \\ e-mail : lienda@che.itb.ac.id
}

\begin{abstract}
Abstrak
Rata-rata bahan baku kaolin di Indonesia masih mempunyai derajat keputihan yang rendah padahal kaolin harus mempunyai derajat keputihan yang tinggi $(>83 \%)$ untuk dapat digunakan sebagai pelapis dalam industri kertas. Untuk meningkatkan derajat keputihan dari bahan baku kaolin tersebut, proses pemutihan perlu dilakukan. Proses pemutihan kaolin telah banyak dilakukan oleh beberapa peneliti dengan menggunakan pemutih yang berbeda-beda. Warna kuning kecokelatan pada kaolin yang menurunkan derajat keputihan kaolin disebabkan oleh kandungan besi (III) oksida dalam kaolin. Pada proses pemutihan, terjadi reduksi besi (III) oksida menjadi besi (II) oksida yang lebih mudah larut dalam air sehingga lebih mudah dipisahkan dari padatan kaolin. Pada penelitian ini, pemutihan kaolin menggunakan $\mathrm{Na}_{2} \mathrm{~S}_{2} \mathrm{O}_{4}$ dan EDTA sebagai pemutih. Penelitian ini bertujuan untuk melihat pengaruh variabel operasi yaitu $\mathrm{pH}$ dan temperatur terhadap derajat keputihan kaolin pada proses pemutihan menggunakan kedua pemutih tersebut. Hasil percobaan menunjukkan proses pemutihan menggunakan $\mathrm{Na}_{2} \mathrm{~S}_{2} \mathrm{O}_{4}$ dan EDTA dapat meningkatkan derajat keputihan kaolin sehingga memenuhi spesifikasi untuk pelapis kertas pada beberapa kondisi operasi. Proses pemutihan berhasil meningkatkan derajat keputihan kaolin hingga mencapai $85,54 \%$ pada $\mathrm{pH} 12$ dan temperatur $70^{\circ} \mathrm{C}$.
\end{abstract}

Kata kunci : kaolin, pemutihan, derajat keputihan, kertas, pelapis

\begin{abstract}
In general, raw kaolin clay of Indonesia still has low brightness even though it needs brightness greater than $83 \%$ to be used as coating in paper industry. In order to increase the brightness, bleaching process is required. The bleaching process of kaolin has been carried out by several researchers using different bleaching agents. The brownish yellow colour of kaolin which reduces its brightness is caused by the content of iron (III) oxide in kaolin. During the bleaching process, reduction of iron (III) oxide takes place producing iron (II) oxide which is more soluble in water hence it can be more easily separated from kaolin solids. In this study, $\mathrm{Na}_{2} \mathrm{~S}_{2} \mathrm{O}_{4}$ and EDTA are used as the bleaching agents. This study aims to investigate the effect of operating variables such as $\mathrm{pH}$ and temperature on the brightness level of kaolin in the bleaching process using the two bleaching agents. The results showed that the process under various operating conditions were able to increase the brightness of kaolin until it met the specification of paper coating. The bleaching process successfully increased the brightness of kaolin up to $85.54 \%$ at $\mathrm{pH}$ of 12 and temperature of $70^{\circ} \mathrm{C}$.
\end{abstract}

Keywords: kaolin, bleaching, brightness, paper, coating

Diterima (received) : 24 November 2018 , Direvisi (revised ) : 01 April 2019, Disetujui (accepted) : 18 April 2019 


\section{PENDAHULUAN}

Kaolin merupakan batuan dari material lempung berwarna putih atau agak keputihan yang memiliki kandungan besi rendah. Kaolin tersusun atas hidrat aluminium silikat $\left(2 \mathrm{H}_{2} \mathrm{O} . \mathrm{Al}_{2} \mathrm{O}_{3} .2 \mathrm{SiO}_{2}\right)$ dengan beberapa mineral penyerta. Mineral yang termasuk kelompok kaolin adalah kaolinit, nakrit, dikrit, dan haloisit dengan kaolinit sebagai mineral utama. Sebagai mineral utama, kaolinit terdiri atas kristal heksagonal berukuran 0,1-10 $\mu \mathrm{m}$. Kaolin terbentuk karena proses pelapukan dan proses hidrotermal alterasi pada bantuan beku yang mengandung feldspar ${ }^{1)}$. Proses pelapukan seperti yang ditunjukkan oleh reaksi 1 terjadi pada permukaan atau sangat dekat permukaan bantuan beku ${ }^{2)}$.

$$
\begin{aligned}
& 2 \mathrm{CaSi}_{3} \mathrm{O}_{8}+2 \mathrm{H}_{2} \mathrm{O}+\mathrm{CO}_{2} \\
& \underset{2 \mathrm{H}_{2} \mathrm{O}+4 \mathrm{SiO}_{2}}{\mathrm{~K}_{2} \mathrm{CO}_{3}} \rightarrow \mathrm{Al}_{2} \mathrm{O}_{3} 2 \mathrm{SiO}_{2} \\
& \text { feldspar kaolin }
\end{aligned}
$$

Kaolin digunakan sebagai bahan baku di berbagai industri. Penggunaan kaolin yang terutama adalah di industri kertas ${ }^{3}$, keramik ${ }^{4)}$, cat ${ }^{5)}$, farmasi ${ }^{6,7)}$, pengolahan minyak bumi 8), dan pestisida ${ }^{9,10)}$. Saat ini, kaolin yang diaktivasi dengan asam dan alumina telah digunakan juga untuk keperluan industri minyak nabati ${ }^{11)}$. Pemanfaatan kaolin sangat ditentukan oleh sifat fisika dan kimia dari senyawa tersebut. Lebih lanjut, hal ini dipengaruhi oleh kondisi geologis saat kaolin terbentuk dan komposisi mineral penyusun. Deposit kaolin dapat berupa sedimen, residu, maupun hidrotermal. Ketiganya mempunyai sifat yang berbeda sehingga perlu dievaluasi terlebih dahulu untuk menentukan penggunaannya. Sifat kaolin secara umum ditunjukkan oleh Tabel ${ }^{2}{ }^{2}$.

Tabel 1.

Sifat-sifat kaolin secara umum

\begin{tabular}{lll}
\hline Parameter & Kriteria & Satuan \\
\hline Warna & Putih & - \\
Kekerasan & $2-2,5$ & Skala Mohs \\
Berat Jenis & $2,60-2,63$ & $\mathrm{~g} \mathrm{~cm}^{-3}$ \\
Indeks Bias & 1,56 & - \\
Titik Lebur & 1850 & ${ }^{\circ} \mathrm{C}$ \\
Daya hantar & Rendah & - \\
panas/listrik & & \\
$\mathrm{pH}$ & bervariasi & - \\
\hline
\end{tabular}

Dalam penelitian ini, kaolin yang diproses diharapkan untuk dapat digunakan sebagai pelapis kertas. Sifat-sifat yang sangat penting untuk aplikasi ini antara lain dispersi, viskositas, kecerahan, derajat keputihan, kilap, kehalusan, kemampuan perekat, kekuatan lapisan, penerimaan tinta, dan kualitas cetak. Untuk dapat digunakan dalam industri kertas, kaolin harus memenuhi spesifikasi yang tertera pada Tabel ${ }^{12}$ ).

Tabel 2.

Spesifikasi kaolin untuk industri kertas

\begin{tabular}{ll}
\hline Warna & Putih \\
\hline Ukuran partikel & Kecil, halus \\
Bentuk partikel & Datar, tipis \\
pH inert & $4-9$ \\
Tekstur & Lembut dan tidak abrasif \\
Kemampuan & Mudah terdispersi dalam \\
dispersi & air dengan kandungan \\
& padatan tinggi (65-72\%) \\
Viskositas & Rendah untuk laju geser \\
& tinggi maupun rendah \\
Toksisitas & Tidak beracun \\
\hline
\end{tabular}

Indonesia memiliki potensi persediaan kaolin yang cukup besar. Menurut Badan Pusat Statistik (2009), ada sekitar 66,21 juta ton cadangan kaolin yang tersebar di beberapa daerah seperti Kalimantan Barat, Kalimantan Selatan, Bangka Belitung, dan sebagian Sulawesi dan Jawa. Dengan jumlah cadangan yang cukup banyak, Indonesia mampu mengekspor kaolin ke Jepang dan Korea Selatan dengan laju pertumbuhan ekspor mencapai 2,62\% pada tahun $2009{ }^{13)}$. Ironisnya, Indonesia ternyata masih perlu mengimpor kaolin dari Cina dan Amerika Serikat dengan laju pertumbuhan sebesar $11,13 \%$. Nilai ekspor kertas berlapis kaolin dari Indonesia juga terus mengalami penurunan sebesar hampir $11 \%$ dari tahun 2012 - $2016^{14)}$.

Kaolin asal Indonesia memiliki mutu yang relatif rendah. Salah satunya adalah masalah derajat kecerahan yang masih rendah. Misalnya, kaolin dari Cicalengka yang hanya memiliki derajat kecerahan sekitar $75 \%{ }^{15}$. Padahal, untuk dapat digunakan di industri kertas, derajat kecerahan minimal $83 \%{ }^{12}$. Kandungan $\mathrm{Fe}_{2} \mathrm{O}_{3}$ yang masih melampaui spesifikasi industri kertas (>1\%) dapat menyebabkan peningkatan colouration pada kertas ${ }^{16)}$.

Secara umum, pemutihan atau bleaching kaolin dapat dilakukan secara kimiawi (agen pemutih), fisik (flotasi dan magnetik), dan biologis. Pemutihan secara fisik, misalnya dengan penggunaan medan magnetik berfungsi untuk memisahkan besi oksida dan hidroksida yang membutuhkan tahapan proses lanjutan yang lebih kompleks dari pemisahan kimiawi 17). Pemisahan dengan agen biologis, yang disebut juga sebagai mineral bio-beneficiation, menyediakan alternatif ramah lingkungan untuk proses 
penghilangan besi oksihidroksida dari kaolin 18). Sebagai contoh, penggunaan fungi Aspergillus niger telah diteliti dan mampu memberikan $47,7 \%$ penghilangan besi pada temperatur $25^{\circ} \mathrm{C}$ dan $38,8 \%$ pada $30^{\circ} \mathrm{C}{ }^{19}$. Pada dasarnya, $A$. niger untuk pemutihan kaolin berperan sebagai penghasil asam oksalat yang mampu mengendapkan ion besi terlarut menjadi besi (II) oksalat dihidrat yang juga dapat diproses lebih lanjut untuk produkproduk lainnya ${ }^{20)}$. Meskipun demikian, proses yang melibatkan agen biologis hingga saat ini masih berada pada skala laboratorium. Agen pemutih seperti $\mathrm{Na}_{2} \mathrm{SO}_{3}$, $\mathrm{Cl}_{2}, \mathrm{HCl}$, dan ditionat dapat digunakan, namun dengan efisiensi pemisahan yang rendah karena terbentuknya kompleks ion besi ${ }^{21}$. Tiourea dioksida umum digunakan untuk pemutih kertas dan tekstil dengan jalan mereduksi ion $\mathrm{Fe}^{3+}$ (tidak larut) menjadi $\mathrm{Fe}^{2+}$ (larut), serta sangat stabil pada $\mathrm{pH}$ netral, memiliki laju penguraian yang rendah, aman dan murah. Sayangnya, pemutihan perlu dilakukan pada $\mathrm{pH}$ di atas sepuluh dan temperatur $70^{\circ} \mathrm{C}$ sehingga menyebabkan kesulitan operasional 22). Penelitian saat ini memanfaatkan milling process untuk menciptakan tiourea dioksida dengan ukuran partikel yang lebih kecil dan seragam sehingga memiliki kontak yang lebih baik dengan reaktan ${ }^{23)}$ dan elemen tanah jarang berinti dua sebagai agen aktivator ${ }^{211}$. Natrium hidrosulfit mampu mengatasi efisiensi yang rendah sehingga digunakan secara komersial saat ini. Meskipun demikian, proses ini harus dilakukan pada $\mathrm{pH}$ kurang dari tiga karena sifat senyawa yang tidak stabil pada $\mathrm{pH}$ netral dan basa sehingga selanjutnya menyebabkan biaya operasional yang tinggi dan tidak ramah lingkungan ${ }^{4)}$.

Selain penggunaan agen bleaching secara tunggal, kombinasi dua agen bleaching telah dilakukan untuk mengoptimumkan efisiensi dan capaian proses. Natrium ditionat $3 \%$ dan asam sulfat telah dicoba pada penelitian sebelumnya pada kondisi $\mathrm{pH} 2$, rasio padat terhadap cairan 1:3, serta waktu reaksi selama 45 menit. Peningkatan derajat kecerahan dari $69,93 \%$ menjadi $81,31 \%$ dan penurunan kadar $\mathrm{Fe}_{2} \mathrm{O}_{3}$ sebesar $0,12 \%$ dari mula-mula $0,52 \%$ berhasil diperoleh ${ }^{24)}$. Meskipun demikian, nilai kecerahan tersebut masih belum memenuhi spesifikasi agar dapat digunakan di industri kertas. Penelitian ini berupaya meningkatkan derajat kecerahan kaolin dari Cicalengka agar dapat digunakan dalam industri kertas. Peningkatan kecerahan dilakukan dengan menggunakan kombinasi dua macam agen bleaching, yaitu natrium ditionat dan EDTA, yang mana variasi ini belum pernah dilakukan oleh penelitian lainnya. Reaksi pemutihan memiliki beberapa variabel operasi seperti temperatur, $\mathrm{pH}$, waktu pengadukan, dan jumlah bleaching agent. Tujuan yang hendak dicapai di antaranya adalah penentuan pengaruh variabel operasi $\mathrm{pH}$ dan temperatur terhadap derajat keputihan kaolin pada proses pemutihan dengan natrium ditionat dan EDTA.

\section{METODE PENELITIAN}

\section{Analisis Bahan Baku}

Bahan baku kaolin diperoleh dari PT Kaolin Salju Abadi Cicalengka dalam keadaan telah dibersihkan dan digerus. Analisis yang dilakukan meliputi analisis kadar $\mathrm{SiO}_{2}$ dan $\mathrm{Al}_{2} \mathrm{O}_{3}$ yang merupakan komponen terbesar dari kaolin, kadar $\mathrm{Fe}_{2} \mathrm{O}_{3}$ yang merupakan zat pengotor dalam kaolin, serta nilai derajat keputihan dari kaolin. Kadar $\mathrm{SiO}_{2}, \mathrm{Al}_{2} \mathrm{O}_{3}$, dan $\mathrm{Fe}_{2} \mathrm{O}_{3}$ ditentukan dengan alat Spektrofotometer Serapan Atom (SSA) sedangkan analisis derajat keputihan dengan menggunakan alat Color Measuring Difference Unit. Keseluruhan analisis ini dilakukan oleh PPTM.

\section{Proses Pemutihan Kaolin}

Kaolin yang akan diputihkan dilarutkan dalam air terbentuk larutan dengan kadar $25 \%$ berat padatan. Ke dalam larutan kemudian ditambahkan dispersing natrium silikat sebanyak $0,25 \%$ berat kaolin. Larutan diaduk dengan kecepatan $100 \mathrm{rpm}$ selama 30 menit pada temperatur ruangan agar kaolin terdispersi dengan baik kemudian didekantasi. Larutan yang didapatkan kemudian diatur pH-nya dengan penambahan $\mathrm{H}_{2} \mathrm{SO}_{4} 1 \mathrm{M}$ dan/atau $\mathrm{NaOH} 1$ M. Setelah $\mathrm{pH}$-nya sesuai dengan yang diinginkan, larutan dipanaskan dalam water bath. Setelah itu, bleaching agent berupa $\mathrm{Na}_{2} \mathrm{~S}_{2} \mathrm{O}_{4}$ sebanyak $3 \%$ dan EDTA $1 \%$ berat kaolin awal ditambahkan ke dalam larutan. Larutan ini kemudian diaduk selama 3 menit dan didiamkan selama 2 jam dengan tetap menjaga temperatur operasi. Setelah itu, larutan difiltrasi dan padatan yang diperoleh dikeringkan dalam oven bertemperatur $120^{\circ} \mathrm{C}$. Selama proses pengeringan, padatan ditimbang setiap lima menit sekali dan pengeringan dihentikan apabila berat padatan sudah konstan selama tiga kali penimbangan. Padatan kering ini kemudian dianalisis derajat keputihan. 
Langkah-langkah

percobaan digambarkan dalam diagram alir percobaan seperti pada Gambar 1.

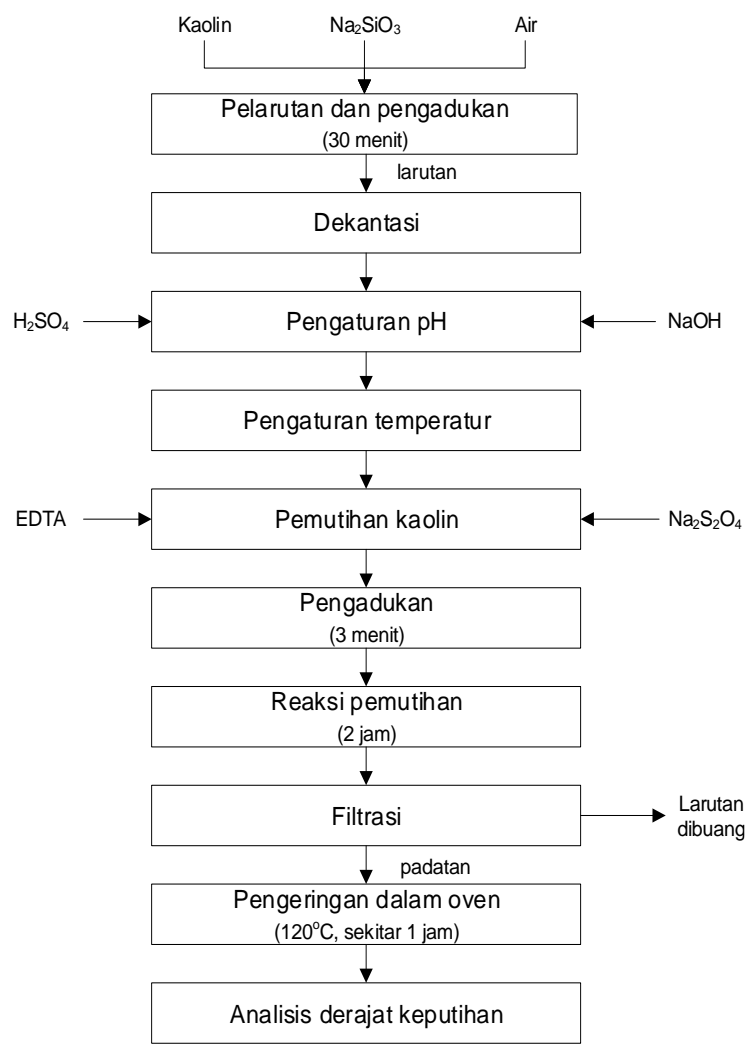

Gambar 1.

Diagram alir percobaan pemutihan kaolin

\section{Analisis Derajat Keputihan}

Analisis derajat keputihan dilakukan terhadap sampel yang telah dikeringkan menggunakan alat Color Measuring Difference Unit. Standar yang digunakan dianggap sebagai benda putih yang dapat memantulkan seluruh sinar yang dipancarkan. Pada percobaan ini, standar berupa $\mathrm{MgO}$ dimasukkan ke dalam alat lalu diatur pada angka $100 \%$. Kemudian sampel dimasukkan ke dalam alat dan angka yang terbaca menunjukkan derajat keputihan sampel. Persentase derajat keputihan menunjukkan proporsi sinar yang dipantulkan oleh sampel dibandingkan sinar yang dipantulkan oleh standar $\mathrm{MgO}$.

\section{Analisis $\mathrm{Kadar} \mathrm{Fe}_{2} \mathrm{O}_{3}$}

Kadar $\mathrm{Fe}_{2} \mathrm{O}_{3}$ yang diukur adalah berat $\mathrm{Fe}_{2} \mathrm{O}_{3}$ dalam sampel kaolin hasil pemutihan terhadap berat kaolin hasil pemutihan. Analisis ini dilakukan menggunakan Spektrofotometer Serapan Atom (SSA) dan diawali dengan pembuatan kurva kalibrasi dari hasil pengukuran absorbansi larutan standar berupa besi sulfat dengan beragam konsentrasi yang telah diketahui. Setelah itu, pengukuran absorbansi dilakukan terhadap sampel kaolin yang telah dikeringkan dan dilarutkan dalam asam sulfat $1 \mathrm{M}$. Angka hasil pengukuran absorbansi dikonversi menjadi konsentrasi berdasarkan kurva kalibrasi yang telah dibuat.

\section{Analisis $\mathrm{Kadar} \mathrm{SiO}_{2}$}

Kadar $\mathrm{SiO}_{2}$ yang diukur adalah berat $\mathrm{SiO}_{2}$ dalam sampel kaolin hasil pemutihan terhadap berat kaolin hasil pemutihan. Analisis $\mathrm{SiO}_{2}$ juga menggunakan Spektrofotometer Serapan Atom (SSA) dan mengikuti prosedur kerja yang sama dengan analisis $\mathrm{Fe}_{2} \mathrm{O}_{3}$ tetapi pelarut yang digunakan bukan asam sulfat melainkan asam klorida.

\section{Perhitungan Perolehan}

Perolehan dihitung dengan cara menimbang berat kaolin hasil pemutihan setelah pengeringan dan setelah disaring dengan ayakan ukuran 325 mesh dibandingkan dengan berat kaolin awal yang akan diputihkan.

\section{HASIL DAN PEMBAHASAN}

\section{Analisis Bahan Baku}

Analisis kimia dan derajat keputihan bahan baku kaolin yang digunakan diperoleh dari data tersebut terlihat derajat keputihan kaolin masih terlalu rendah dan belum dapat digunakan sebagai pelapis kertas. Seperti diulas sebelumnya, sebagai pelapis kertas kaolin harus memiliki derajat keputihan minimal $83 \%$ Bahkan, derajat keputihan untuk pelapis kertas yang diproduksi oleh beberapa produsen di luar negeri memiliki spesifikasi derajat keputihan yang lebih tinggi. Rendahnya derajat keputihan ini disebabkan tingginya kadar $\mathrm{Fe}_{2} \mathrm{O}_{3}$ dalam kaolin, yaitu mencapai $1,9 \%$ padahal kandungan $\mathrm{Fe}_{2} \mathrm{O}_{3}$ dalam kaolin sebagai pelapis kertas seharusnya kurang dari $1 \%$. Agar dapat digunakan sebagai pelapis kertas, kadar $\mathrm{Fe}_{2} \mathrm{O}_{3}$ dalam kaolin harus dikurangi.

\section{Pengaruh pH terhadap Derajat Keputihan}

Hasil percobaan dengan variabel operasi $\mathrm{pH}$ pada berbagai temperatur dapat dilihat pada Gambar 3. Pada rentang pH 2 4 , derajat keputihan cenderung menurun. Reaksi yang dominan terjadi adalah reaksi 
pelarutan besi oksida dalam air ${ }^{25}$, seperti reaksi (2) dan (3).

$\mathrm{Fe}_{2} \mathrm{O}_{3}+\mathrm{H}_{2} \mathrm{O} \rightleftharpoons \mathrm{Fe}(\mathrm{OH})_{3}$

$\mathrm{Fe}(\mathrm{OH})_{3} \rightleftharpoons \mathrm{Fe}^{3+}+3 \mathrm{OH}^{-}$

$\mathrm{Ksp} \mathrm{Fe}(\mathrm{OH})_{3}=4.10^{-38}$

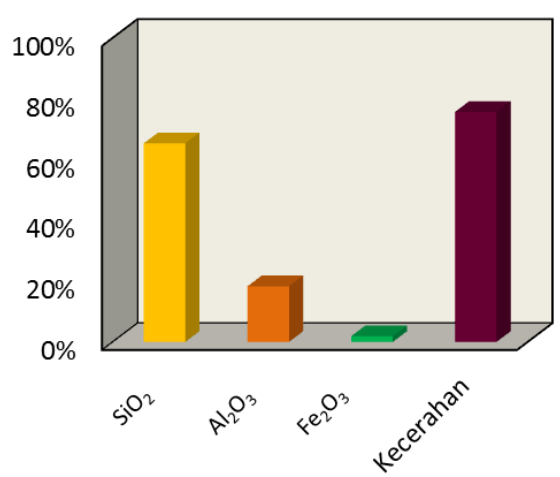

Gambar 2.

Analisis kimia dan derajat kecerahan bahan baku kaolin

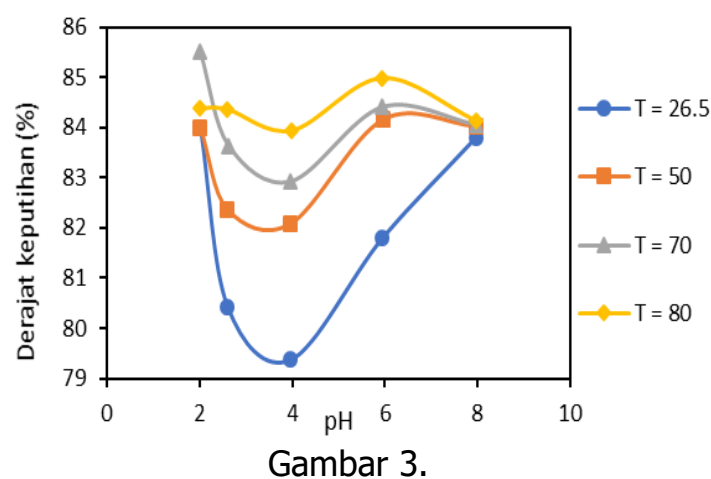

Hasil percobaan dengan variabel operasi $\mathrm{pH}$ untuk beberapa temperatur

Dari nilai kelarutan besi (III) oksida terlihat bahwa untuk kenaikan dari $\mathrm{pH} 2$ menjadi $\mathrm{pH}$ 4, kelarutan $\mathrm{Fe}_{2} \mathrm{O}_{3}$ dalam air menjadi sepersepuluh ribu nilai kelarutan semula. Penurunan kelarutan ini diduga belum dapat diimbangi oleh kenaikan kemampuan EDTA (nilai Kef EDTA- $\mathrm{Fe}^{3+}$ ) ${ }^{26}$. Selain itu, pada $\mathrm{pH}$ rendah terjadi reaksi penguraian ditionat ${ }^{27}$ ). Penguraian ion ditionat oleh $\mathrm{H}^{+}$menurut reaksi (4).

$2 \mathrm{~S}_{2} \mathrm{O}_{4}{ }^{2-}+4 \mathrm{H}^{+} \rightleftharpoons 3 \mathrm{SO}_{2}+\mathrm{S}+2 \mathrm{H}_{2} \mathrm{O}$

Dengan adanya ditionat yang terurai maka reaksi reduksi $\mathrm{Fe}_{2} \mathrm{O}_{3}$ menjadi $\mathrm{FeO}$ yang mempunyai kelarutan lebih besar akan berkurang sehingga didapatkan derajat keputihan yang lebih rendah.

Pada rentang $\mathrm{pH} 4-6$, derajat keputihan yang diperoleh semakin meningkat. Hal ini diduga disebabkan adanya peningkatan kemampuan pengikatan ion besi oleh EDTA. Pada pH 6, nilai Kef dari reaksi EDTA-Fe jauh lebih besar dibandingkan nilainya pada $\mathrm{pH}$ 4. Dengan nilai $\mathrm{K}_{\text {ef }}$ yang besar maka jumlah ion besi yang dapat terkompleksasi menjadi makin banyak. Dengan berkurangnya ion besi bebas dalam air maka kesetimbangan reaksi pelarutan besi oksida akan bergeser ke kanan yang berarti jumlah besi oksida yang dapat dipisahkan semakin besar.

Pada $\mathrm{pH}$ yang mendekati netral, kemampuan EDTA meningkat dan penguraian ion ditionat oleh $\mathrm{H}^{+}$juga tidak terjadi. Dengan tidak adanya ditionat yang terurai maka reaksi reduksi $\mathrm{Fe}_{2} \mathrm{O}_{3}$ menjadi FeO dapat terjadi dan besi oksida yang terlarutkan makin banyak. Peran kedua bleaching agents (EDTA dan natrium ditionat) sangat dominan pada rentang $\mathrm{pH} 4$ - 6. EDTA berperan dalam mengikat ion $\mathrm{Fe}$ menurut reaksi (5) dan (6).

$$
\begin{aligned}
& \mathrm{Y}^{4-}+\mathrm{Fe}^{3+} \rightleftharpoons \mathrm{FeY}^{-} \\
& \mathrm{Y}^{4-}+\mathrm{Fe}^{2+} \rightleftharpoons \mathrm{FeY}^{2-}
\end{aligned}
$$

Sedangkan natrium ditionat berguna sebagal reduktor yang akan mereduksi $\mathrm{Fe}_{2} \mathrm{O}_{3}$ menjadi $\mathrm{FeO}$ dimana kelarutan $\mathrm{Fe}(\mathrm{OH})_{2}$ sebagai bentuk hidrat dari $\mathrm{FeO}$ jauh lebih besar dibandingkan $\mathrm{Fe}(\mathrm{OH})_{3}{ }^{24)}$.

Reaksi natrium ditionat dan $\mathrm{Fe}_{2} \mathrm{O}_{3}$ adalah seperti pada reaksi (7) ${ }^{27)}$. $\mathrm{Na}_{2} \mathrm{~S}_{2} \mathrm{O}_{4}+\mathrm{Fe}_{2} \mathrm{O}_{3}+2 \mathrm{H}_{2} \mathrm{O} \rightarrow 2 \mathrm{FeO}+$
$\mathrm{Na}_{2} \mathrm{SO}_{3}+\mathrm{H}_{2} \mathrm{SO}_{3}+\mathrm{H}_{2} \mathrm{O}$

Pada rentang $\mathrm{pH} 6-8$ dan temperatur tinggi $\left(50,70\right.$, dan $\left.80^{\circ} \mathrm{C}\right)$, terjadi penurunan derajat keputihan karena reaksi pelarutan besi oksida kembali dominan. Tetapi pada temperatur kamar, reaksi penguraian natrium ditionat tidak berlangsung sehingga terjadi peningkatan derajat keputihan. Natrium ditionat akan mereduksi $\mathrm{Fe}_{2} \mathrm{O}_{3}$ menjadi $\mathrm{FeO}$ yang mempunyai kelarutan lebih besar. Kelarutan $\mathrm{Fe}(\mathrm{OH})_{3}$ dan $\mathrm{Fe}(\mathrm{OH})_{2}$ akan diperbesar oleh reaksi kompleksasi EDTA-Fe di mana reaksi ini akan menggeser reaksi pelarutan besi oksida ke kanan (prinsip kesetimbangan Le Chatelier) sehingga jumlah besi oksida yang dapat dipisahkan akan semakin besar meskipun nilai kelarutannya pada $\mathrm{pH} 8$ lebih kecil dibandingkan pada $\mathrm{pH}$ 6. Dengan demikian, pada rentang $\mathrm{pH}$ ini, reaksi yang dominan adalah reaksi (5) dan (6).

Berdasarkan hasil percobaan, bleaching agents yang digunakan terbukti cukup efektif untuk meningkatkan derajat keputihan kaolin. Unjuk kerja dari bleaching agent natrium 
ditionat ditentukan oleh jumlah natrium ditionat yang terurai di mana penguraiannya sangat dipengaruhi oleh $\mathrm{pH}$. Dengan demikian, perlu dilakukan percobaan lanjutan dengan variasi jumlah natrium ditionat pada $\mathrm{pH}$.

\section{Pengaruh Temperatur terhadap Derajat Keputihan}

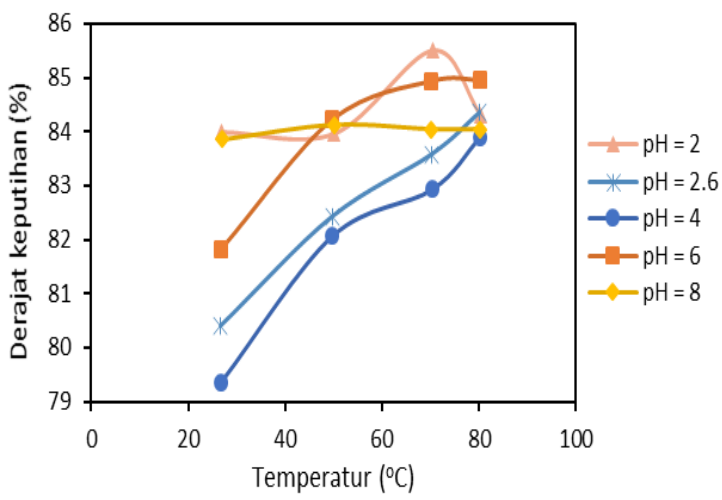

Gambar 4.

Hasil pemutihan pada beberapa temperatur operasi

Hasil percobaan dengan variabel operasi temperatur pada berbagai $\mathrm{pH}$ dapat dilihat pada Gambar 4 yang menunjukkan bahwa terjadi peningkatan kecerahan seiring dengan kenaikan temperatur karena terjadi peningkatan kelarutan besi oksida dalam air. Akan tetapi, pada $\mathrm{pH} 2$, derajat keputihan justru menurun pada kenaikan temperatur dari $70^{\circ} \mathrm{C}$ menjadi $80^{\circ} \mathrm{C}$. Hal ini disebabkan kenaikan temperatur juga menyebabkan penguraian ditionat. Penguraian ini terjadi menurut reaksi (8).

$$
2 \mathrm{~S}_{2} \mathrm{O}_{4}{ }^{2-}+\mathrm{H}_{2} \mathrm{O} \rightleftharpoons 2 \mathrm{HSO}_{3}^{-}+\mathrm{S}_{2} \mathrm{O}_{3}{ }^{2-}
$$

Reaksi penguraian ini dipercepat oleh adanya oksigen dan $\mathrm{pH}$ yang rendah. Selain itu, reaksi penguraian ditionat juga dapat berlangsung menurut reaksi (3) pada $\mathrm{pH} 2$ untuk kenaikan temperatur dari $70^{\circ} \mathrm{C}$ menjadi $80^{\circ} \mathrm{C}$. Oleh karena pengaruh reaksi (4) dan (8), derajat keputihan yang diperoleh mengalami penurunan.

Pengaruh temperatur terhadap derajat keputihan cenderung mengecil pada $\mathrm{pH}$ yang semakin tinggi seperti yang terlihat pada $\mathrm{pH}$ 8 di mana kenaikan temperatur hampir tidak meningkatkan kecerahan. Hal ini disebabkan kelarutan besi oksida dalam air menjadi sangat kecil pada $\mathrm{pH}$ yang tinggi sehingga adanya peningkatan temperatur hampir tidak mempengaruhi derajat keputihan.

\section{Analisis $\mathrm{Kadar} \mathrm{Fe}_{2} \mathrm{O}_{3}$}

Hasil analisis kandungan $\mathrm{Fe}_{2} \mathrm{O}_{3}$ pada beberapa sampel yang dapat mewakili beberapa derajat keputihan dapat dilihat pada Gambar 5. Gambar tersebut membuktikan bahwa semakin tinggi kandungan $\mathrm{Fe}_{2} \mathrm{O}_{3}$ dalam kaolin, derajat keputihannya semakin rendah.

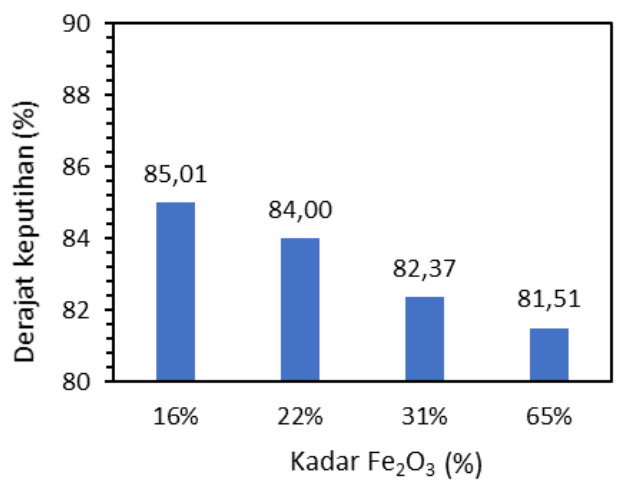

Gambar 5.

Hasil analisis kandungan $\mathrm{Fe}_{2} \mathrm{O}_{3}$ dan derajat keputihan beberapa sampel kaolin

\section{Analisis Kadar $\mathrm{SiO}_{2}$}

Hasil analisis kandungan $\mathrm{SiO}_{2}$ pada beberapa sampel yang telah memenuhi spesifikasi ukuran partikel dan derajat keputihan ditunjukkan oleh Gambar 6 . Berdasarkan Gambar 6, kandungan $\mathrm{SiO}_{2}$ masih terlalu besar dibandingkan spesifikasi umum kandungan $\mathrm{SiO}_{2}$ pada kaolin yang digunakan sebagai pelapis kertas yaitu sekitar 47\%. Hal ini diperkirakan sebagai penyebab derajat keputihan kaolin masih kurang dari $86 \%$. Kecerahan kaolin diperkirakan masih dapat ditingkatkan dengan cara pengurangan kandungan $\mathrm{SiO}_{2}$ dalam kaolin sebelum diputihkan.

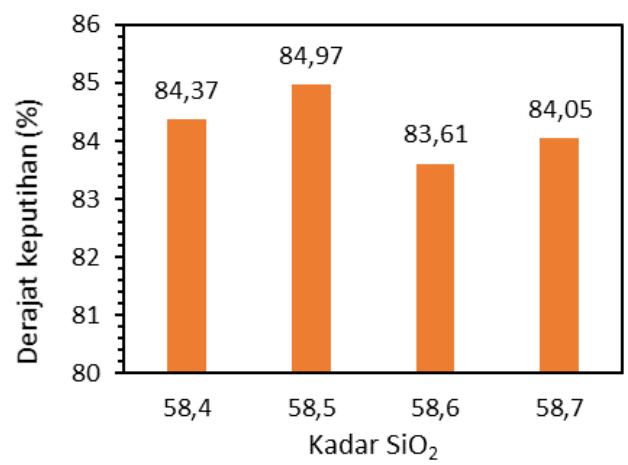

Gambar 6.

Hasil analisis kandungan $\mathrm{SiO} 2$ dan derajat keputihan beberapa sampel kaolin 


\section{Pengaruh Filtrat yang Terjebak dalam Padatan}

Pada percobaan yang dilakukan, terdapat filtrat dari proses filtrasi larutan kaolin hasil pemutihan yang terjebak dalam padatan kaolin. Persentase volume filtrat yang terjebak dalam padatan kaolin hasil filtrasi diasumsikan sama untuk setiap percobaan. Kadar besi oksida yang terlarut namun tidak terpisahkan dari padatan kaolin hasil pemutihan ditunjukkan oleh Tabel 3 .

Tabel 3

Kandungan $\mathrm{Fe}_{2} \mathrm{O}_{3}$ yang berasal dari filtrat kaolin hasil pemutihan

\begin{tabular}{cc}
\hline $\begin{array}{c}\mathrm{Fe}_{2} \mathrm{O}_{3} \text { kaolin hasil } \\
\text { pemutihan (\%) }\end{array}$ & $\mathrm{Fe}_{2} \mathrm{O}_{3}$ filtrat (\%) \\
\hline 0,7 & 0,07 \\
0,6 & 0,07 \\
0,5 & 0,08 \\
0,4 & 0,09 \\
0,3 & 0,09 \\
0,2 & 0,1 \\
0,15 & 0,1 \\
0,1 & 0,1 \\
\hline
\end{tabular}

Pada Tabel 3 terlihat bahwa semakin kecil kadar $\mathrm{Fe}_{2} \mathrm{O}_{3}$ dalam kaolin hasil pemutihan, jumlah $\mathrm{Fe}_{2} \mathrm{O}_{3}$ yang berasal dari filtrat akan semakin besar sehingga jumlah besi oksida yang terlarutkan tetapi tidak dapat dipisahkan dari padatan kaolin juga semakin besar. Ini akan mengakibatkan kandungan $\mathrm{Fe}_{2} \mathrm{O}_{3}$ dalam kaolin tidak akan dapat dipisahkan seluruhnya dan nilai $\mathrm{Fe}_{2} \mathrm{O}_{3}$ akan terbatas dan tidak akan mencapai $100 \%$.

\section{SIMPULAN}

Penelitian ini menunjukkan bahwa reaksi pemutihan kaolin dipengaruhi oleh variabel operasi $\mathrm{pH}$ dan temperatur. Secara umum derajat keputihan kaolin hasil pemutihan berkurang pada kondisi operasi antara $\mathrm{pH} 2$ dan $\mathrm{pH} 4$ kemudian meningkat antara $\mathrm{pH} 4$ dan $\mathrm{pH} 6$ dan berkurang kembali antara $\mathrm{pH} 6$ dan $\mathrm{pH} 8$ kecuali pada temperatur kamar. Sementara itu, kenaikan temperatur operasi menyebabkan kenaikan derajat keputihan kaolin kecuali pada temperatur di atas $70^{\circ} \mathrm{C}$ untuk $\mathrm{pH}$ 2. Selain itu, jumlah filtrat yang terjebak dalam padatan kaolin mempengaruhi kandungan $\mathrm{Fe}_{2} \mathrm{O}_{3}$ dalam kaolin hasil pemutihan. Dengan demikian, pemutihan kaolin Cicalengka menggunakan
EDTA dan natrium ditionat dalam skala industri sebaiknya dilakukan pada $\mathrm{pH} 6$ dan temperatur $70^{\circ} \mathrm{C}$, yang merupakan kondisi optimum untuk mencapai derajat keputihan kaolin sebesar $85,54 \%$.

\section{DAFTAR PUSTAKA}

1. Cygan, R. T. dan Tazaki, K. Interactions of Kaolin Minerals in the Environment. Elements 10, 195-200 (2014).

2. Sukandarrumadi. Bahan Galian Industri. (UGM Press, 2018).

3. dos Santos, I. R., Ventorim, G., Caraschi, J. C. dan Comelato Favaro, J. S. Analysis of pulp bleaching sequences in the retention of kaolin and in the properties of paper. Rev. Arvore 39, 1147-1154 (2015).

4. Chen, Y. et al. Effect of rice hulls additions and calcination conditions on the whiteness of kaolin. Ceram. Int. 40, 11751-11758 (2014).

5. Štengl, V., Popelková, D. dan Grygar, T. M. Composite pigments based on surface coated kaolin and metakaolin. Appl. Clay Sci. 101, 149-158 (2014).

6. Awad, M. E., López-Galindo, A., Setti, M., El-Rahmany, M. M. dan Iborra, C. V. Kaolinite in pharmaceutics and biomedicine. Int. J. Pharm. 533, 34-48 (2017).

7. Aleanizy, F. S., Alqahtani, F., Al Gohary, O., El Tahir, E. dan Al Shalabi, R. Determination and characterization of metronidazole-kaolin interaction. Saudi Pharm. J. 23, 167-176 (2015).

8. Hafez, A. I., Gerges, N. S., Ibrahim, H. N., Abou El-magd, W. S. I. dan Hashem, A. I. Evaluation of kaolin clay as natural material for transformer oil treatment to reduce the impact of ageing on copper strip. Egypt. J. Pet. 26, 533-539 (2017).

9. Khairy, M., Ayoub, H. A., Rashwan, F. A. dan Abdel-Hafez, H. F. Chemical modification of commercial kaolin for mitigation of organic pollutants in environment via adsorption and generation of inorganic pesticides. Appl. Clay Sci. 153, 124-133 (2018).

10.Amalin, D. M., Averion, L., Bihis, D., Legaspi, J. C. dan David, E. F. Effectiveness of Kaolin Clay Particle Film in Managing Helopeltis collaris (Hemiptera: Miridae), a Major Pest of Cacao in the Philippines. Florida Entomol. 98, 354-355 (2015).

11.Aung, L. L., Tertre, E., Suksabye, P., Worasith, N. dan Thiravetyan, P. Erratum to: Effect of alumina content and surface area of acid-activated kaolin on bleaching 
of rice bran oil. JAOCS, J. Am. Oil Chem. Soc. 92, 621 (2015).

12.H. Murray, H. dan Kogel, J. E. Engineered clay products for the paper industry. Appl. Clay Sci. 29, 199-206 (2005).

13. Hryadi, H. Perkembangan dan prospek bahan galian nonlogam indonesia. $J$. Teknol. Miner. dan Batubara 6, 45-63 (2010).

14.Statistik Perdagangan. (2017). doi:ISSN: $0852-9078$

15.Aini, M. N. dan Indriati, L. Proses pemutihan zeolit sebagai bahan pengisi kertas. J. Selulosa 42, 23-28 (2007).

16.Gougazeh, M. Removal of iron and titanium contaminants from Jordanian Kaolins by using chemical leaching. J. Taibah Univ. Sci. 12, 247-254 (2018).

17.Campos, V. M. J. S., Bertolino, L. C. dan Alves, O. C. Mineralogical characterization and beneficiation study of kaolin from Equador (RN) and Junco do Seridó (PB) to increase the brightness index. Ceramica 63, 369-375 (2017).

18. Hosseini, M. R. dan Ahmadi, A. Biological beneficiation of kaolin: A review on iron removal. Appl. Clay Sci. 107, 238-245 (2015).

19. Hajihoseini, J. dan Fakharpour, M. Effect of temperature on bioleaching of iron impurities from kaolin by Aspergillus niger fungal. J. Asian Ceram. Soc. 7, 82-89 (2019).

20.Taran, M. dan Aghaie, E. Designing and optimization of separation process of iron impurities from kaolin by oxalic acid in bench-scale stirred-tank reactor. Appl. Clay Sci. 107, 109-116 (2015).

21.Cao, W., Xia, G., Lu, M., Huang, H. dan $\mathrm{Xu}, \mathrm{Y}$. Iron removal from kaolin using binuclear rare earth complex activated thiourea dioxide. Appl. Clay Sci. 126, 6367 (2016).

22.Makarov, S. V, Horváth, A. K., SilaghiDumitrescu, R. dan Gao, Q. Recent Developments in the Chemistry of Thiourea Oxides. Chem. - A Eur. J. 20, 14164-14176 (2014).

23.Lu, M., Xia, G. dan Zhang, X. Refinement of industrial kaolin by removal of ironbearing impurities using thiourea dioxide under mechanical activation. Appl. Clay Sci. 141, 192-197 (2017).

24.Li, J. T. et al. Orthogonal experiments for kaolin bleaching by using sodium dithionite and sulfuric acid. Advanced Materials Research 968, 116-124 (2014).

25.Chatman, S., Zarzycki, P. dan Rosso, K. M. Spontaneous Water Oxidation at Hematite (a-Fe2O3) Crystal Faces. ACS Appl. Mater. Interfaces 7, 1550-1559 (2015).

26. Borggaard, O. K. Selective extraction of amorphous iron oxides by EDTA from a Danish sandy loam. J. Soil Sci. 30, 727734 (1979).

27. Varadachari, C., Goswami, G. dan Ghosh, K. Dissolution of Iron Oxides. Clay Research 25, (2006). 